Transportation Research Forum

Estimating Elasticities for Multi-Modal Public Transport Demand: A Time Series Approach Author(s): Konstantina Gkritza, Ioannis Golias, and Matthew G. Karlaftis

Source: Journal of the Transportation Research Forum, Vol. 43, No. 2 (Fall 2004), pp. 53-68

Published by: Transportation Research Forum

Stable URL: http://www.trforum.org/journal

The Transportation Research Forum, founded in 1958, is an independent, nonprofit organization of transportation professionals who conduct, use, and benefit from research. Its purpose is to provide an impartial meeting ground for carriers, shippers, government officials, consultants, university researchers, suppliers, and others seeking exchange of information and ideas related to both passenger and freight transportation. More information on the Transportation Research Forum can be found on the Web at www.trforum.org. 


\section{Estimating Elasticities for Multi- Modal Public Transport Demand: A Time Series Approach}

Research on the demand side of public transportation systems with the use of time series data frequently shows conflicting results with respect to fare elasticities and the factors affecting it. In this analysis we complement prior research by developing seemingly unrelated regression equation models with monthly data for a city served by three different modes of public transportation. The results indicate that, as expected, urban public transport demand in Athens, Greece, is inelastic with respect to fares but, surprisingly, highly inelastic with respect to automobile fuel cost. Further, different transit modes have significantly different fare elasticities, a finding with important practical implications.

\section{by Konstantina Gkritza, Ioannis Golias, and Matthew G. Karlaftis}

\section{INTRODUCTION}

In recent years, much of the literature on public transportation, or transit, has concentrated on issues dealing with the cost structure and productivity of the sector. These are extremely important considerations in every regulated industry, both for policy makers and firms. The empirical results regarding the production function of transit firms, along with information on price elasticities of demand, average cost, marginal cost and fare levels, are invaluable tools in the integrated investigation of the efficiency and the market penetration potential of transit systems. In most studies, the price elasticities of demand are estimated from the underlying production function, thus avoiding their direct estimation (Button, 1993).

The direct estimation of demand elasticities as well as the determination of the factors that affect demand are two very important considerations. For example, transit agencies are interested in estimating the demand for service and the corresponding system revenues for operating reasons; if revenues can cover operating cost the transit agency can operate without requiring subsidies. From the above it becomes clear that it is important to directly assess the effect of fare changes on demand particularly because the role of public transport is of vital importance to modern societies, and public resources for subsidies are limited. To this end, accurate knowledge of fare elasticities and of the factors that affect demand is an important consideration in transit research.

This paper is primarily concerned with estimating fare elasticities in a multi-modal public transportation system where different modes may act competitively or complementarily to each other. To achieve this, the paper uses an econometric analysis of the demand for transit services utilizing monthly time-series data from the three modes of public transportation in Athens, Greece. Although the main objective is to estimate fare elasticities, transit service and fuel price elasticities are also estimated.

The remainder of this paper is organized as follows: the next section reviews findings from earlier studies concerned with estimating transit elasticities; in the third section the methodology and the data used in the paper are presented; the empirical results are discussed in the fourth section, where the coefficients from different specifications are presented; and finally, in the fifth section, the findings of the study are summarized and some concluding remarks are offered. 


\section{BACKGROUND}

\section{Empirical Findings of Previous Studies}

Numerous studies assessed the magnitude of transport elasticities. Extensive literature reviews undertaken by Goodwin $(1988,1992)$ and Oum et al. $(1990,1992)$ complement each other, even though their origins and motivations were different.

Goodwin's (1988, 1992) reviews are primarily concerned with empirical estimates of demand elasticities of public transit system and automobile usage. The estimated elasticities are subdivided according to data type ("before and after" studies, time-series investigations, and equilibrium models) and length of the investigation period (short run, long run). It was found that in the short term, public transit demand remains inelastic enough to raise revenue by increasing fares an effective policy. In the long run, the effectiveness of fare increases to increase revenue is reduced, and fare reductions become more effective in enhancing revenue because transit demand is more elastic in the long run. Overall, there appears to be a reasonably clear pattern where long-term elasticities were $50 \%$ to three times higher than short-term elasticities. Goodwin's (1992) findings on urban travel elasticities with respect to length of response time showed that price elasticities become more elastic as travelers have more time to adjust. This observation applies to different modes of urban travel: urban metro system (urban rail and underground travel system), bus travel, and combined bus and metro system. Longterm elasticities appear to be about two times higher than short-term ones. In addition, metro travel demand seems to be more elastic than bus travel demand.

Oum et al. $(1990,1992)$ deal with theoretical and empirical issues in estimating transport demand elasticities in addition to reviewing empirical elasticity estimates for both freight and passenger demand. Unlike Goodwin $(1998,1992)$, they do not report the mean values of the elasticities, but list the entire range of estimates. All the estimates show that the demand for automobile usage and urban transit is unambiguously price inelastic. From the perspective of policymaking, the low-elasticity estimates of automobile usage indicate that monetary incentives may not be very effective in controlling automobile usage in urban areas. After reviewing more than 60 empirical studies of transport demand, Oum et al. (1990, 1992) identify a number of issues that can cause different elasticity estimates which they believe warrant attention. The most important of these are: the presence of intermodal competition, the functional specification of the models, the degree of data aggregation, and the different time horizons and study locations.

It is worth noting that, apart from the reasons for the disparities among elasticity estimates mentioned above, there is an additional issue not touched upon in either article as indicated by Dargay (1993). This issue deals with non-symmetric or irreversible price effects or hysteresis in the demand relationship. The hysteresis argument proposes that consumers may not respond similarly to rising and falling prices, as is traditionally assumed, but instead react in a more complex fashion, depending not only on the direction and the magnitude of the price change, but also on the previous price history.

An analysis of causes of variances between price elasticity values across four European countries (Norway, Finland, the Netherlands, and the United Kingdom) is presented by Nijkamp and Pepping (1998). It appears that from the entire set of variables examined that country, number of competitive modes, and type of data have the strongest explanatory power for the elasticity size (Table 1). The result of the meta-analytic application is that, in addition to the practical findings on the difference between empiricalbased research methods and the use of disaggregated choice models, country-specific characteristics play a large role (e.g. natural circumstances, travel distances, culture, and quality of public transport). The authors conclude that care should be taken when comparing elasticities for different European countries even when estimation methods are the same (i.e. data used and model speci- 
Estimating Elasticities for Multi-Modal Public Transport Demand

Table 1: Results of Meta-Analysis of Transport Price Elasticities for Public Transport in Two European Countries

\begin{tabular}{|c|c|c|c|c|c|c|c|c|c|}
\hline Study & Country & $\begin{array}{c}\text { Yesr of } \\
\text { Data } \\
\text { Collection }\end{array}$ & $\begin{array}{c}\text { Level of } \\
\text { Aggregation }\end{array}$ & $\begin{array}{c}\text { Indicator of } \\
\text { Transport } \\
\text { Demand }\end{array}$ & $\begin{array}{l}\text { Geographical } \\
\text { Coverage }\end{array}$ & $\begin{array}{c}\text { Number of } \\
\text { Competitive } \\
\text { Modes }\end{array}$ & Data Type & Model Type & $\begin{array}{l}\text { Elasticity } \\
\text { Value }\end{array}$ \\
\hline 1 Sullstrom, 1995 & Finland & $1966-90$ & $\begin{array}{l}\text { Bus, tram, } \\
\text { metro, train }\end{array}$ & Person-km & $\begin{array}{c}\text { Urban, } \\
\text { Interurbain }\end{array}$ & 1 & $\begin{array}{c}\text { Repeated } \\
\text { Cross-section }\end{array}$ & $\begin{array}{l}\text { Linear } \\
\text { Demand }\end{array}$ & -0.75 \\
\hline 2 EXTRA Project & Netherlands & 1984-85 & $\begin{array}{l}\text { Bus, tram, } \\
\text { metro }\end{array}$ & Trips & $\begin{array}{l}\text { Urban, Semi- } \\
\text { urban }\end{array}$ & 2 & Panel & $\begin{array}{l}\text { Linear } \\
\text { Demand }\end{array}$ & $\begin{array}{l}-0.35 / \\
-0.40\end{array}$ \\
\hline $3 \mathrm{BGC}, 1988$ & Netherlands & $1980-1986$ & $\begin{array}{l}\text { Bus, tram, } \\
\text { metro }\end{array}$ & Trips & $\begin{array}{l}\text { Urban, Semi- } \\
\text { urban }\end{array}$ & 2 & Time Series & $\begin{array}{l}\text { Linear } \\
\text { Demand }\end{array}$ & $\begin{array}{l}-0.35 / \\
-0.40\end{array}$ \\
\hline 4 Roodenburg, 1983 & Netherlands & $1950-80$ & $\begin{array}{l}\text { Bus, tram, } \\
\text { metro }\end{array}$ & Person-km & $\begin{array}{l}\text { Urban, Semi- } \\
\text { urban }\end{array}$ & 1 & Time Series & $\begin{array}{l}\text { Linear } \\
\text { Demand }\end{array}$ & -0.51 \\
\hline 5 Fase, 1986 & Netherlands & $1965-81$ & $\begin{array}{l}\text { Bus, tram, } \\
\text { metro }\end{array}$ & Person-km & Urban & I & Time Series & $\begin{array}{l}\text { Linear } \\
\text { Demand }\end{array}$ & $\begin{array}{l}-0.53 / \\
-0.80\end{array}$ \\
\hline 6 Oum, 1992 & Netherlands & $1977-91$ & $\begin{array}{c}\text { Bus, lram, } \\
\text { melro }\end{array}$ & Person-km & $\begin{array}{c}\text { Urban, Semi- } \\
\text { urban }\end{array}$ & 2 & Time Series & $\begin{array}{c}\text { Translog } \\
\text { utility }\end{array}$ & -0.74 \\
\hline
\end{tabular}

Source: Nijkamp and Pepping (1998).

fication). They recommend that pricing policies for public transport should be adapted to local situations in order to be able to derive optimal effects.

The demand for local bus services in Great Britain was investigated by the Department of the Environment, Transport and Regions (DETR). The main objective of the study, as reported in Dargay and Hanly (2001), was to obtain estimates of fare elasticities that could be used in policy scenarios to project the change in bus patronage nationally as a result of a given average fare change, and to explore possible variation in elasticity estimates. The estimation of bus fare elasticities is based on annual national and regional aggregate data for the years between 1974 and 1996 for bus patronage, fares and other relevant factors influencing bus use. The estimations use dynamic econometric models relating per capita bus patronage (all journeys) to real per capita income, real bus fares (average revenue per journey) and service level (bus vehicle kilometers). In addition, a structural model was estimated to test for the interaction between bus patronage, motoring costs, and car ownership and use. The results indicate that bus patronage is relatively fare-sensitive, with an elasticity for all of Great Britain of 0.4 in the short run and at -0.9 in the long run. The evidence suggests that the long-run elas-ticities are at least twice those of the short-run elasticities and the total response to a price change takes about seven years. There are indications that full-fare passengers are less sensitive to fare changes than the average bus passenger. The negative relationship between car ownership and bus patronage is confirmed only in the long run. The cross elasticity between bus patronage and motoring costs appears to be negligible in the short run and about 0.3 to 0.4 in the long run.

Gilbert and Jalilian (1991) investigated the demand for travel and for travelcards on London's regional transport system. A simple model was developed in which decisions to travel are jointly determined with decisions to purchase a particular form of ticket (regular or farecard). The results indicate that the demand for bus travel is much more priceresponsive than is the demand for underground (subway) travel; and, both sets of demand elasticities are higher in the long run than in the short run. Indeed, in the long run, bus travel is price elastic (that is, its own-price elasticity exceeds unity) while underground services are price inelastic. This implies that a rise in bus fares, with underground and British Rail fares held constant, would result in a fall in bus revenue. The estimated crossprice elasticities show a high (0.9) cross elasticity of demand for bus services with respect to the underground (subway) price, but much lower cross elas-ticities for the underground services relative to the bus service price (0.35).

The impacts of fare changes, service supply, income and other factors on the demand for public transport are analyzed in a 
study by Bresson et al. (2003). They used data from panels of English counties and French urban areas. Both short and long-run elasticities are estimated with the use of dynamic econometric models. Estimated elasticities for France and England are compared by using a common set of variables, similar time period and a common methodology. The results show a considerable variation in elasticities among different areas within each country. The resulting fare elasticities for the two countries lie in the interval of $(-0.2,-0.5)$ in the short run and ($0.5,-0.8)$ for the long run. These are in the upper range of the estimates found in the literature. The major conclusion is that public transport demand is relatively sensitive to fare changes, so that policy measures aimed at fare reduction (subsidization) can play a substantial role in encouraging the use of public transport, thus reducing the use of private cars. The effects of such measures will be greater in the long run than in the short run, but adjustment is relatively rapid, with $99 \%$ of the total price effect realized within six years.

Johansen (2001) reviews estimates of demand elasticities for local public transport from a number of Norwegian studies. The objective of his study was to assess the effect of fare changes on demand, as local public transport in Norway is financed mainly by the users (fares determine $75 \%$ of the revenues with subsidies being modest at an average of about $25 \%$ ), while the county authorities regulate fares and the level of service. In general, a price elasticity of -0.38 and a service elasticity of $\mathbf{- 0 . 4 2}$ were found for Norway.

Hensher and Raimond (1996) attempted to determine the degree to which travel decisions of Sydney residents change in response to changes in public transport fares. The aim of the study was to obtain information on traveler sensitivity to fare changes on each of the main modes of urban passenger transport: metro system, bus and ferry. The results indicate that travel decisions do not vary significantly with fare changes. As might be expected, commuters are generally less sensitive to fare changes than are non- commuters for the equivalent ticket type and mode. In addition, sensitivity to price increases from single-trip tickets to multipletrip tickets, with very interesting implications for fare policy; this implies that, by increasing the price of a single-trip ticket, revenue growth will be greater and patronage losses smaller than that of weekly tickets.

Finally, and following a completely different thought process, Karlaftis and Golias $(2001,2002)$ investigated whether traffic characteristics and network efficiency parameters influence automobile ownership, as well as whether not having an automobile is also affected (and to what degree), by these parameters. Their results clearly suggested that the variables affecting automobile ownership and non-ownership are not the same. They further suggest that traffic network and efficiency parameters do not affect the decision not to own a car, but they do affect the number of automobiles owned by a household.

\section{Summary of Findings of Previous Studies and Contribution of this Study}

What becomes quite apparent from this brief review of previous work is that elasticity values vary depending upon the type of data collected, the estimation methods, the country, and the number of competitive modes included in the estimation. It appears that country-specific factors play a large role in elasticity estimation. Natural circumstances and travel distances may mean that certain modes are favored; cultural differences and differences in the infrastructure and the quality of public transport may also determine the level of competitiveness between the transport modes. This suggests that care should be taken when comparing elasticities for different metro-politan areas even when estimation methods are the same (i.e. data used and model specification). As a result, a study of price elasticities must be adapted to local conditions so that pricing policies for public transport will be based on the correct elasticities. Given this, the paper will estimate transit elasticities in Athens, Greece. 
The greater Athens urban area is served by three modes of public transportation: a bus, an electric bus and a significant metro system (comprised of a surface urban rail and a subway system). All three modes are subsidiaries of the Athens Urban Transport Authority. Despite their administrative connection, these modes are allowed to make individual decisions regarding operating issues such as the network and routes served, hours of operation and so on. As such, the modes may complement each other, but may also act as competitors in many situations. The above conditions offer a unique opportunity for investigating public transit elasticities in a multi-modal context where different modes may act competitively or complementarily. Taking this into consideration, the paper provides a methodological approach and results concerning:

1. A multimodal public transport system, and

2. Complex administrative and operating conditions for the public transport modes serving the same network, where the modes may act competitively and/or complementarily with each other.

\section{DATA AND METHODOLOGY}

\section{Characteristics of the Athens \\ Metropolitan Area Public \\ Transportation System}

Athens covers an area of 60 square kilometers and has a population of approximately 3.7 million people. During the last decade the population has increased by about $10 \%$ while at the same time car ownership has increased considerably, approaching 250 automobiles per 1,000 inhabitants. The mobility index (congestion related index that shows the percentage of time the level of service measured by the volume/capacity ratio does not reach congestion levels) has decreased by $4 \%$. This has led to a $26 \%$ increase in travel time in the last 12 years which, along with the inadequate urban road network in the central areas, has led to a deterioration of traffic conditions in the capital. Further, the modal split in Athens has changed in favor of automobile travel, with the modal share of automobiles rising from $45 \%$ in 1983 to $54.5 \%$ in 1996 . Correspondingly, the public transport share fell from $40 \%$ (1983) to $31.7 \%$ (1996) (Table 2).

For the Athens Metropolitan area, there is a daily demand for 5.65 million journeys, with a 1.08 million two-hour peak demand. There are 6.3 million single mode daily trips, a $26 \%$ increase in the last 12 years. From this information, it appears that there are 1.72 daily trips per person ( 1.54 journeys/person), while $55 \%$ of the population makes at least one trip per day. It should be noted that a single mode trip refers to a single-leg trip with one mode, while a journey refers to traveling by more that one mode and involves transfers. Figure 1 describes the purpose of travel for a typical weekday.

Athens is served by a bus network of 1,800 vehicles, 1,500 of which are in operation daily, 356 electric buses, 290 of which are in operation daily, and a metro system (com-prised of a surface urban rail and a subway system). The bus system is made up of 41 trunk lines, 116 central lines, 9 intermunicipal lines, 98 local-feeder lines, 8 express lines, and 6 school lines, with a total annual ridership of 403 million passengers.

Table 2: Modal Split in the Athens Metropolitan Area

\begin{tabular}{ccccc}
\hline & $\begin{array}{c}\text { Public } \\
\text { Transport }\end{array}$ & Automobile & Taxi & Walk \\
\hline 1983 & $40 \%$ & $45 \%$ & $6.0 \%$ & $9 \%$ \\
1996 & $31.7 \%$ & $54.5 \%$ & $6.0 \%$ & $7.8 \%$ \\
\hline
\end{tabular}

Source: MAM, Metro Development Study (2000). 
Figure 1: Purpose of Travel for a Typical Weekday

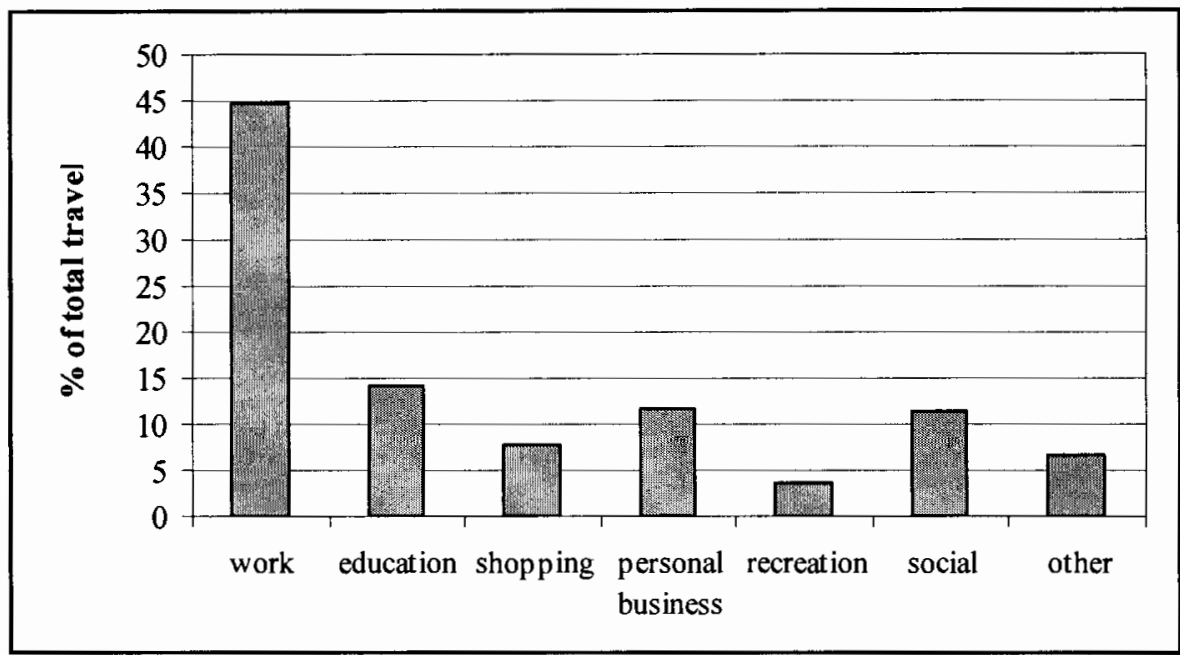

Source: MAM, Metro Development Study (2000).

The electric bus network has 26 lines with annual ridership of 90 million passengers. The metro system serves a network of 44 kilometers through three separate railway lines (two of which are underground) with annual ridership of 92 million passengers. More than 1.9 million passengers use the integrated services provided throughout the city on working days. As for the Athens road network, it has had a $3.5 \%$ annual increase in traffic for the last 10 years, and $22 \%$ of its signalized intersection approaches in the center of the city are highly congested.

\section{The Data}

The estimation of public transport demand elasticities is based on monthly aggregate data from January 1995 to April 2001. The variables included in the dataset are public transport patronage, fares, vehicle kilometers, automobile ownership, and socioeconomic and demographic factors similar to those indicated as significant by the literature. All transport data for the variables in Table 3 were obtained from the Athens Urban Transport Organization. The macroeconomic and demographic data were obtained from various sources including the National Statistical Service of Greece (unemployment rate, number of immigrants), the Greek Ministry of Transportation (automobile ownership, fuel price index) and the Bank of Greece (Consumer Price Index, per capita income).

As measures of public transport demand, ticket and travelcard sales were selected.

Table 3: Transport, Macroeconomic, and Demographic Variables

\begin{tabular}{ll}
\hline Transport Variables & $\begin{array}{l}\text { Macroeconomic and Demographic } \\
\text { Variables }\end{array}$ \\
\hline $\begin{array}{l}\text { Urban Public Transport Patronage } \\
\text { (ticket sales, travelcard sales) }\end{array}$ & Automobile ownership \\
$\begin{array}{l}\text { Fare levels } \\
\text { (per mode and category) }\end{array}$ & Fuel costs \\
Vehicle kilometers & Consumer Price Index (CPI) \\
Monthly hours of strikes & Per capita income \\
& Unemployment rate \\
& Number of immigrants \\
\hline
\end{tabular}


Vehicle kilometers for each mode of public transport were used to measure transit supply. Fare levels were taken into account through ticket prices and travelcard prices. Note that the fare structure involves a flat fare for using buses and electric buses and a zonal fare for using the metro. Students and military personnel are eligible to pay half the ticket price. In addition, two different types of travelcards are available: one that allows travel on both the bus and the electric bus systems and another that allows travel on all three modes of public transport. Both types of travelcards are issued monthly. Automobile ownership is measured as the number of vehicles registered in the greater Athens urban area. Fuel costs are taken into account through the fuel price index (base year 1997). The Consumer Price Index demonstrates the trends in consumer prices and inflation in Greece (base year 1999), and is used to deflate the fare prices.
Tables 4 and 5 show the mean and the standard deviation for the transportation (Table 4), macroeconomic and demographic variables (Table 5). The statistics presented in both tables were obtained on a monthly basis from 1995 to 2001 .

\section{Methodology}

In transportation studies it is possible to have a series of dependent variables that may be considered as a group, yet do not have direct interaction as they would in common simultaneous equation models. For example, in the public transport demand problem examined in this paper, the demand for the three modes may be examined by estimating three separate equations with the demand for each mode as the dependent variable. However, because all three dependent variables are from the same underlying process (public transport demand), the three equations are likely to share

Table 4: Monthly Descriptive Statistics for the Transport Variables

\begin{tabular}{lcc}
\hline Transport Variable & Mean & Standard Deviation \\
\hline Bus Full-Ticket Sales & $12,177,863$ & $1,665,396$ \\
Electric Bus Full-Ticket Sales & $3,887,266$ & 711,663 \\
Metro Full-Ticket Sales & $9,239,413$ & $1,518,694$ \\
Bus Half-Ticket Sales & $2,148,238$ & 579,434 \\
Electric Bus Half-Ticket Sales & 89,679 & 53,953 \\
Metro Half-Ticket Sales & $1,380,583$ & 366,376 \\
\hline Bus Travelcard Sales & 86,055 & 23,948 \\
Electric Bus Travelcard Sales & 71,462 & 12,930 \\
Metro Travelcard Sales & 63,476 & 14,804 \\
\hline Bus and Electric Bus Full Fare & 0.32 & 0.06 \\
Metro Full Fare & 0.46 & 0.14 \\
Travelcard Price for Buses and Electric Buses & 15.37 & 2.28 \\
Travelcard Price for All Modes & 26.93 & 4.05 \\
\hline Bus Vehicle-kilometers & $7,744,048$ & 522,438 \\
Electric Bus Vehicle-kilometers & 947,732 & 91,868 \\
Metro Vehicle-kilometers & $1,450,217$ & 135,638 \\
\hline Monthly Hours of Bus Strikes & 18 & 16 \\
Monthly Hours of Electric Bus Strikes & 23 & 11 \\
Monthly Hours of Metro Strikes & 19 & 22 \\
\hline
\end{tabular}

Note: Ticket sales are measured by the number of ticket holders; travelcard sales are measured by the number of travelcards sold on a monthly basis; ticket fares and travelcard prices are in Euro $(\epsilon)$.

Source: Athens Urban Transport Organization (www.oasa.gr). 
Table 5: Monthly Descriptive Statistics for Macroeconomic and Demographic Variables

\begin{tabular}{lcc}
\hline Macroeconomic and & Mean & Standard Deviation \\
\hline Demographic Variables & $1,393,354$ & 181,945 \\
Automobile Ownership & 93 & 20 \\
Fuel Price Index & 9 & 2 \\
Unemployment Rate & 94 & 8 \\
Consumer Price Index & 487 & 9 \\
Income per Capita & 165,183 & 9,758 \\
Number of Immigrants &
\end{tabular}

Note: Unemployment rate is given as a percentage; per capita income is in Euro $(\epsilon)$.

Sources: Greek Ministry of Transportation (www.yme.gov.gr); Bank of Greece (www.bankofgreece.gr); National Statistical Service of Greece (www.statistics.gr).

unobserved characteristics. The equations are thus seemingly unrelated, but they have contemporaneous (cross-equation) correlation of their error terms. If the equations are estimated separately by ordinary least squares (OLS), the parameter estimates are consistent but not efficient. Efficient parameter estimates are obtained by considering the contemporaneous correlation of the disturbances. Considering contemporaneous correlation in seemingly unrelated equations is referred to as SURE (seemingly unrelated equations estimation) (Washington et al., 2003).

As noted, the equations are related through the correlation in the errors. Therefore, instead of considering one equation at a time, the equations are aggregated and their coefficients $(\beta)$ are estimated according to the following procedure. Consider a set of $M$ seemingly uncorrelated equations with the $i$ th equation given by:

$$
y_{i}=X_{i} \cdot \beta_{i}+\varepsilon_{i}, i=1, \ldots, M
$$

where $y_{i}$ is a Txl vector of observed values on the $i$ th dependent variable, $X_{i}$ is a $\mathrm{T} \times p_{i}$ matrix with rank $p_{i}$ of observations on $p_{i}$ independent variables, $\beta$ is a $p_{i} \times 1$ vector of unknown regression coefficients, and $\varepsilon_{i}$ is a Tx1 vector of error terms. It is assumed that $\varepsilon=\left(\varepsilon_{1}, \varepsilon_{2}, \ldots, \varepsilon_{M}\right)$ has a multivariate normal density with mean $\mathrm{E}[\varepsilon]=0$ and covariance $\mathrm{E}\left[\varepsilon \varepsilon^{\prime}\right]=\sum \otimes I_{T}=\mathrm{V}$, where $\sum=\left(\sigma_{i j}\right)$ is a positive symmetric matrix and $I_{T}$ is a TxT identity matrix and $\otimes$ is the Kroneger product. The generic equation can be written, similar to a linear regression model, as:

(2)

$$
Y=X \beta+\varepsilon
$$

where $Y=\left(y_{1}, y_{2}, \ldots, y_{M}\right)$

$\beta=\left(\beta_{1}, \beta_{2}, \ldots, \beta_{M}\right)$ and $X=I_{T} \otimes X_{i}$. Using Generalized Least Squares (GLS), a best linear unbiased estimator is obtained:

(3) $\hat{\beta}=\left\{X^{\prime}\left(\Sigma \otimes I_{T}\right)^{-1} \cdot X\right\}^{-1} \cdot X^{\prime}\left(\Sigma \otimes I_{T}\right)^{-1} \cdot Y$

The estimator $\hat{\beta}$ (known as seemingly unrelated restricted residuals estimator) is at least as efficient as the estimator of obtained by using the ordinary least squares method (OLS) on each of the $M$ equations given in equation (1).

The basic functional form used in this paper is the double logarithmic (log-log) SURE model. In this kind of model specification, the estimators $\hat{\beta}$ show the percentage change in demand for dependent variable $y$ induced by a $1 \%$ change in the independent variables $X_{i}$; that is they indicate the demand elasticity. The dependent variables examined are public transport patronage (bus, electric bus, and metro ticket and travelcard sales). The independent variables in each equation capture the basic dimensions of demand determination: own cost (fare price), competitor cost and supply (automobile fuel price and number of automobiles in circulation), transit service supply (vehicle kilometers operated), 
macroeconomic and demographic characteristics (unemployment rate, per capita income, and number of immigrants) and a number of other important system characteristics (monthly hours of employee strikes and a dummy variable indicating the extension to the metro system from one line to three lines in January of 2000). It should be noted that, for the test of the significance of the independent variables, the $t$-test (student) is used at the $10 \%$ level of significance.

Previous research suggest that public transport patronage seems to be negativelyrelated to fare levels, automobile ownership, monthly hours of employee strikes, and per capita income; and positively-related to transit service supply, automobile fuel costs, unemployment rate and number of immigrants. The negative relationship of public transit demand to per capita income indicates that public transit is an inferior good. The positive relationship to unemployment rate and number of immigrants suggests that both groups (unemployed individuals and immigrants) seem to be captive public transport riders, i.e. they can't afford automobiles.

\section{DEMAND FUNCTION ESTIMATION: EMPIRICAL RESULTS}

\section{SURE Model Estimation and Interpretation}

The models presented in Tables 6 and 7 are the results of the SURE methodology applied to public transport demand ${ }^{1}$ (ticket and travelcard sales). The independent variables include price variables, transport variables and other macroeconomic factors similar to those indicated as significant in the literature. The price variables include full fare ticket price, (average) travelcard price and average ticket price divided by travelcard price (which demonstrates the relative price of a ticket to the price of a travelcard). All price variables were introduced in each model with and without hysteresis (time lag of one month, as suggested by Dargay, 1993). However, only the results of the final model specifications with the average ticket price divided by travelcard price as a price variable are presented in the following tables. In the interest of brevity the results of other equations with alternative price specifications are not included because the estimated coefficients did not vary much between the equations. Modeling of travelcard sales is done for both types of travelcards available: one that allows travel on both the bus and the electric bus systems and another that allows travel on all three modes of public transport. Finally, it should be noted that the full set of available independent variables is presented in Table 6, while Table 7 displays only the independent variables that are statistically significantly at the 0.10 level.

The results reported in Table 6 indicate a number of interesting, mostly expected, findings. In general, increases in ticket over travelcard prices lead to a decrease in ticket sales in favor of travelcards for all three modes. Increases in service supply $\mathrm{S}$ in terms of vehicle kilometers $\mathrm{S}$ lead to an increase in ticket sales for all three modes, as expected. However, employee strikes that result in a decrease in the amount of service provided do not seem to affect public transport demand. Interestingly, automobile ownership has a significant negative impact only on electric bus ticket sales. Increases in fuel prices lead to an increase in bus and metro ticket sales indicating that people prefer using public transport (buses or metro) when automobile costs increase. Increases in per capita income decrease bus and metro ticket sales indicating that both modes are inferior goods. Finally, increases in unemployment lead to an increase in bus ticket sales as a result of an increase in bus riders, but have no significant impact on electric bus or metro ticket sales. The metro system is not influenced by unemployment increases because it does not serve many industrial or lower income areas. In addition, the cost for riding a bus is lower that that for metro, as it is indicated in Table 4, and thus, bus seems a more attractive public transport mode for lower-income groups.

Regarding travelcard sales, the results in Table 7 imply that increases in ticket prices lead to an increase in travelcard sales for all modes, as expected. The demand for both 
Estimating Elasticities for Multi-Modal Public Transport Demand

Table 6: Model Results for Ticket Sales

\begin{tabular}{|c|c|c|c|c|c|c|}
\hline \multirow{2}{*}{$\begin{array}{c}\text { Dependent Variables } \\
\text { Independent Variables }\end{array}$} & \multicolumn{2}{|c|}{ Bus Ticket Sales } & \multicolumn{2}{|c|}{ Electric Bus Ticket Sales } & \multicolumn{2}{|c|}{ Metro Ticket Sales } \\
\hline & $\begin{array}{l}\text { Coefficient } \\
\text { Estimate }\end{array}$ & t-statistic & $\begin{array}{c}\text { Coefficient } \\
\text { Estimate }\end{array}$ & t-statistic & $\begin{array}{c}\text { Coefficient } \\
\text { Estimate }\end{array}$ & t-statistic \\
\hline Constant & 8.609 & 7.349 & 50.376 & 3.805 & 10.860 & 0.932 \\
\hline $\begin{array}{l}\text { Average ticket price over travelcard } \\
\text { price (time lag } 1 \text { month) }\end{array}$ & -0.110 & -4.438 & -0.117 & -4.244 & -0.002 & -1.498 \\
\hline Bus vehicle kilometres & 0.226 & 2.028 & na & $n a$ & na & na \\
\hline Electric bus vehicle kilometres & $n a$ & $n a$ & 0.372 & 3.149 & na & $n a$ \\
\hline Metro vehicle kilometres & $n a$ & $n a$ & $n a$ & $n a$ & 0.273 & 1.896 \\
\hline Total vehicle kilometres & $n s$ & ns & $n s$ & $n s$ & $n s$ & $n s$ \\
\hline Bus strikes & $n s$ & ns & na & $n a$ & $n a$ & $n a$ \\
\hline Electric bus strikes & $n a$ & $n a$ & $n s$ & $n s$ & na & $n a$ \\
\hline Metro strikes & na & $n a$ & na & na & ns & ns \\
\hline Automobile ownership & $n s$ & $n s$ & -7.331 & -3.084 & $n s$ & $n s$ \\
\hline Fuel price index & 0.177 & 2.086 & $n s$ & $n s$ & 0.127 & 1.216 \\
\hline Income per capita & -1.422 & -3.043 & $n s$ & $n s$ & -1.132 & -1.394 \\
\hline Unemployment rate & 0.141 & 2.514 & $n s$ & $n s$ & $n s$ & $n s$ \\
\hline Tíme & -0.005 & -4.556 & $n s$ & $n s$ & $n s$ & $n s$ \\
\hline \multicolumn{7}{|l|}{ Summary Statistics } \\
\hline Number of observations & \multicolumn{2}{|l|}{76} & \multicolumn{2}{|c|}{76} & \multicolumn{2}{|c|}{76} \\
\hline $\mathrm{R}^{2}$ & \multicolumn{2}{|l|}{0.830} & \multicolumn{2}{|c|}{0.830} & \multicolumn{2}{|c|}{0.895} \\
\hline
\end{tabular}

a. $n s$ indicates statistically not significant variables.

b. na indicates not applicable variables.

Table 7: Model Results for Travelcard Sales

\begin{tabular}{|c|c|c|c|c|}
\hline \multirow{2}{*}{$\begin{array}{c}\text { Dependent Variables } \\
\text { Independent Variables }\end{array}$} & \multicolumn{2}{|c|}{$\begin{array}{l}\text { Travelcard Sales for buses } \\
\text { and electric buses }\end{array}$} & \multicolumn{2}{|c|}{$\begin{array}{l}\text { Travelcard Sales for all public modes } \\
\text { modes of transport }\end{array}$} \\
\hline & Coefficient Estimate & t-statistic & Coefficient Estimate & t-statistic \\
\hline Constant & 16.697 & 1.003 & 2.767 & 0.199 \\
\hline Average ticket price/travelcard price & 1.132 & 8.400 & 0.050 & 60.893 \\
\hline Total vehicle kilometres & 0.672 & 3.329 & 0.430 & 1.976 \\
\hline Fuel price index & $n s$ & $n s$ & 0.204 & 1.519 \\
\hline Unemployment rate & 0.162 & 1.890 & -0.440 & -2.954 \\
\hline \multicolumn{5}{|l|}{ Summary Statistics } \\
\hline Number of observations & \multicolumn{2}{|l|}{76} & \multicolumn{2}{|l|}{40} \\
\hline $\mathrm{R}^{2}$ & \multicolumn{2}{|l|}{0.872} & \multicolumn{2}{|l|}{0.938} \\
\hline
\end{tabular}

* $n s$ indicates statistically not significant variable. 
types of travelcards is positively related to vehicle kilometers. Increases in fuel prices lead to an increase in travelcard sales for all modes but have no significant impact on bus or electric bus travelcard sales. Increases in unemployment rates increase travelcard sales for buses and electric buses but the effect is negative for all modes combined, probably because the metro system does not serve neighborhoods that suffer significantly from unemployment.

\section{Public Transport Demand Elasticities}

The estimates of demand elasticities for the three main modes of public transportation are summarized in Tables 8 and 9. The elasticities shown in the following tables are obtained from the estimators $\hat{\beta}$ in the different model specifications that use various definitions for the price variable. However, as noted previously only the models with average ticket price/travelcard price as the price variable were presented in the interest of brevity because the coefficients of the variables did not change much as the price variable was altered. Most of the coefficients in Table 8 are in Table 6. It was also of interest to examine the impact of the extensions to the metro system from one line to three lines (in January 2000) on the demand elasticities for bus ticket sales. To achieve this, the different model specifications indicated by the previous analysis were applied to two separate datasets consisting of 61 observations (before metro extension) and 15 (after metro extension) respectively. Table 8 presents the different elasticity estimates for bus ticket sales for the before and after the metro extension periods, as well as for the entire period (76 observations).

Table 8 displays the elasticity estimates of public transport patronage (ticket sales) by mode of transport (bus, electric bus, metro). The results indicate that the demand for urban public transport for all public modes is fairly inelastic in regard to fares, irrespective of the form of the price variable. It also appears that demand for metro travel is much less priceresponsive than is demand for bus travel
$(-.002$ versus -0.110$)$. It is worth noting that similar results were reported in the investigation of the demand for travel and for travelcards on London regional transport (Gilbert and Jalilian, 1991) where it was determined that a rise in fares appears to have a stronger negative impact on bus demand than it has on metro demand. Moreover, it appears that after the metro extension the bus riders have become more sensitive to fares than before because they are offered more travel choices.

Elasticity estimations of service level of supply (vehicle kilometers) for urban public transport indicate that the demand for all modes of transport is inelastic with respect to the service supply level of each mode. Regarding bus users, it appears that after the metro extension they have become more sensitive to the levels of service supply than before.

Another important result is that the demand for public transport is rather insensitive to auto fuel prices; the cross-price elasticity for bus and metro system demand amounts to 0.177 and 0.127 , respectively. Interestingly, the coefficient for fuel price in the case of electric buses is not significant, possibly due to the characteristics of the area served by this mode. These low elasticity estimates were also confirmed by many preceding empirical studies such as Rus (1990) and Oum et al. (1992).

Table 9 contains estimates of travelcard demand elasticities. The classification of results is by different types of travelcards; one that allows travel on both the bus and electric bus systems and another that allows travel on all three modes of public transport. Some of the elasticities in Table 9 were obtained from estimated equations with alternative specifications of the price variable. The other elasticities are from Table 7 . The results indicate that travelcard sales are inelastic with respect to fares (for most price variables used) and are also more fare-sensitive than ticket sales (for all price variables used). The analysis according to travelcard type led to the conclusion that travelcard sales for buses and electric buses are more price responsive 
Estimating Elasticities for Multi-Modal Public Transport Demand

Table 8: Ticket Sales Demand Elasticities

\begin{tabular}{lccccc}
\hline \multicolumn{1}{c}{ Elasticitien } & \multicolumn{5}{c}{ Ticket Sales } \\
\cline { 2 - 6 } & Bus & $\begin{array}{c}\text { Bus } \\
\text { Before } \\
\text { Metro Extenslon }\end{array}$ & $\begin{array}{c}\text { Bus } \\
\text { After }\end{array}$ & Electric Bus & Metro \\
\hline Full fare ticket price (same month) & $n s$ & $n s$ & $n s$ & $n s$ & $n s$ \\
Full fare ticket price (time lag l month) & -0.117 & -0.019 & -0.220 & $n s$ & $n s$ \\
Average ticket price/ travelcard price & $n s$ & $n s$ & $n s$ & $n s$ & $n s$ \\
Average ticket price/travelcard price & -0.110 & -0.017 & -0.450 & -0.117 & -0.002 \\
(time lag 1 month) & 0.226 & 0.064 & 0.451 & 0.372 & 0.273 \\
Bus or Mettro Vehicle kilometres & $n s$ & $n s$ & $n s$ & $n s$ & $n s$ \\
Total Vehicle kilometres & 0.177 & $n s$ & $n s$ & $n s$ & 0.127 \\
Fuel price index & & & & & $n$
\end{tabular}

* $n s$ indicates statistically not significant variables.

Table 9: Travelcard Demand Elasticities

\begin{tabular}{lcc}
\hline \multicolumn{1}{c}{ Elasticlties } & \multicolumn{2}{c}{ Travelcard Sales } \\
\cline { 2 - 3 } & $\begin{array}{c}\text { For buses and electric } \\
\text { buses }\end{array}$ & For all public modes \\
\hline Travelcard price for buses and electric buses & -0.766 & $n a$ \\
Travelcard price for all public modes of transport & $n a$ & -0.189 \\
Average travelcard price for buses and electric buses & -0.762 & $n a$ \\
Average travelcard price for all public modes of transport & $n a$ & -0.669 \\
Average ticket price/travelcard price for buses and electric buses & 1.132 & $n a$ \\
Average ticket price/travelcard price for all public modes & $n a$ & 0.050 \\
Total Vehicle kilometres & 0.672 & 0.430 \\
Fuel price index & $n s$ & 0.204 \\
\hline
\end{tabular}

a. $n s$ indicates a statistically not significant variable.

b. na indicates not applicable variables. 
than travelcard sales for all modes of transport. The demand for travelcards seems to be also inelastic with respect to the service supply level (total kilometers) provided for both bus and electric bus only and for all modes. Finally, the observation that the demand for public transport is rather insensitive to fuel prices is also confirmed by the low elasticity estimate for the fuel price index shown in Table 9.

\section{Short-run and Long-run Elasticities of Demand}

In time-series models for bus demand, a substantial period of time may pass between the economic decision-making period and the final impact of a change in a price variable. In order to estimate the long-run price elasticities for bus demand, an appropriate model in-cluding lagged variables was used. In the classical regression model, the response of $y$ to a change in $x$ is assumed to be immediate and to be completed by the end of the period of measurement. In a distributed lag model, a one-time change in $x_{t}$ at any point in time will affect $\mathrm{E}\left[y_{t}\right]$ in every period thereafter. If the level of $x$, has been unchanged for many periods prior to $t$, then the equilibrium value of $\mathrm{E}\left[y_{1}\right]$ (assuming that it exists) will be:

$$
\bar{y}=\alpha+\sum_{i=0}^{\infty} \beta_{i} \bar{x}=\alpha+\bar{x} \cdot \sum_{i=0}^{\infty} \beta_{i}
$$

where $\bar{x}$ is the permanent value (long-run equilibrium) of $x_{i}$. For this value to be finite (that is, changes in $x$ cease to have any influence after a fairly small number of periods), it is required that:

$$
\left|\sum_{i=0}^{\infty} \beta_{i}\right|<\infty
$$

The short-run effect $(\beta)$ is the one that occurs in the same period as the change in $x$. The long-run effect derives from the equilibrium multiplier.

$$
\beta=\sum_{i=0}^{\infty} \beta_{i}
$$

The lag coefficients $\beta_{i}$ that denote the bus demand elasticities for the full-fare ticket price are presented in Table 10 .

Although the unlagged elasticity is the theoretical short-run elasticity, the long-run elasticity was compared to the one month lagged elasticity since the unlagged elasticity was not significant. All the estimates show that the demand for bus usage is fairly inelastic. The long-run price elasticity $(-0.530)$ - estimated as the sum of the lag coefficients $\beta_{i}$ that are presented in Table $10-$ is found to be higher than the price elasticity one month after the price change (-0.117), and consistent with other surveys of urban transit demand such as Goodwin (1988, 1992), Gilbert and Jalilian (1991), and Dargay and Hanly (2001). However, it appears that bus demand in Athens is less fare sensitive in comparison to other European cities (Table 1). A 10\% increase in fares is likely to induce a $1.17 \%$ decrease in bus demand one month after the price change, and a $5.3 \%$ decrease in the long run (eight months after the price change).

Table 10: Bus Demand Lagged Elasticities

\begin{tabular}{lc}
\hline \multicolumn{1}{c}{ Lagged Variables } & $\begin{array}{c}\text { Elasticities } \\
\text { (t-statistic) }\end{array}$ \\
\hline Full fare ticket price (unlagged) & \\
\hline Full fare ticket price (time lag 1 month) & $\begin{array}{c}-0.117 \\
(-4.244)\end{array}$ \\
\hline Full fare ticket price (time lag 2 months) & $\begin{array}{c}-0.103 \\
(-4.598)\end{array}$ \\
\hline Full fare ticket price (time lag 3 months) & $\begin{array}{c}-0.088 \\
(-4.467)\end{array}$ \\
\hline Full fare ticket price (time lag 4 months) & $\begin{array}{c}-0.071 \\
(-4.038)\end{array}$ \\
\hline Full fare ticket price (time lag 5 months) & $\begin{array}{c}-0.056 \\
(-3.249)\end{array}$ \\
\hline Full fare ticket price (time lag 6 months) & $\begin{array}{c}-0.042 \\
(-2.628)\end{array}$ \\
\hline Full fare ticket price (time lag 7 months) & $\begin{array}{c}-0.031 \\
(-1.856)\end{array}$ \\
\hline Full fare ticket price (time lag 8 months) & $\begin{array}{c}-0.022 \\
(-1.296)\end{array}$ \\
\hline
\end{tabular}




\section{DISCUSSION AND CONCLUSIONS}

The goal of this paper was to assess the sensitivity of travelers to public transport travel costs in Athens, as well as to other factors that influence demand. Modeling urban public transport demand was achieved by applying econometric analysis (Seemingly Unrelated Regression Equations, SURE), based on monthly aggregate data from January of 1995 to April of 2001 for public transport patronage, fares, and other relevant factors influencing public transport use.

The main finding from this study is that urban public transport demand is inelastic with respect to fares. This conclusion applies to both ticket and travelcard sales. However, travelcard sales seem to be more fare sensitive in comparison to ticket sales. It can also be concluded by the analysis based on the classification of travelcards (travelcards for buses and electric buses and travelcards for all modes of public transport) that travelcard sales for buses and electric buses are more price responsive than travelcard sales for all modes of transport. It also appears that different modes of public transport have significantly different fare elasticities, a finding with very important practical implications. Moreover, elasticity estimates indi- cate that bus travelers became less captive to this specific mode of transport once the metro network was extended from one to three lines, possibly indicating that the three different modes of public transport may act competitively in many circumstances. Another important result is that the demand for public transport is rather insensitive to fuel prices. There seems to be an interesting initial indication that car travelers seem to perceive automobile use to be an essential good, while public transport travel appears to be an inferior good as indicated by the negative income elasticities.

Note that some of the results in this study are consistent with preceding empirical studies, while some differ from others. This is a rather expected conclusion because in previous reviews (Oum et al., 1992 and Nijkamp and Pepping, 1998), it was pointed out that studies in different cities or countries often find markedly different elasticity estimates, even when the estimation methods are the same. Many of the conclusions reached in this study may prove beneficial for public transport operators in their effort to assess the behavioral implications of the implementation of a new fare system, as well as to best manage the existing one.

\section{Endnote:}

1. Public transport demand is a phenomenon that cannot be directly measured. It can best be approximated as the sum of ticket sales, i.e. the number of ticket holders that board a bus and travelcard sales (travelcards are issued monthly and allow for unlimited traveling for a given set of public transport modes). Although public transport demand is the sum of these two measures, separate models are estimated to allow for the possibility of differential elasticity measures. 


\section{References}

Athens Urban Transport Organization (www.oasa.gr).

Bank of Greece (www.bankofgreece.gr).

Bresson G, D. Dargay, J-L. Madre, and A. Pirotte. "The Main Determinants of the Demand for Public Transport: A Comparative Analysis of England and France Using Shrinkage Estimators."

Transportation Research Part A 000 (article in press), (2003).

Button K. (Ed.). Transport Economics, Second Edition. Elgard Publishing, Aldershot, 1993.

Dargay J. "Demand Elasticities: A Comment." Journal of Transport Economics and Policy 27 (1), (1993): 87-90.

Dargay J. and M. Hanly. "Bus Patronage in Great Britain: An Econometric Analysis." Transportation Research Part A, (2001).

Gilbert C.L. and H. Jalilian. "The Demand for Travel and for Travelcards on London Regional Transport." Journal of Transport Economics and Policy 25 (1), (1991): 3-29.

Goodwin P.B. "Evidence on Car and Public Transport Demand Elasticities." Transport Studies Unit, Working Paper 427, University of Oxford, Oxford, England, 1988.

Goodwin P.B. "A Review of New Demand Elasticities with Special Reference to Short and Long Run Effects of Price Changes." Journal of Transport Economics and Policy 26 (2), (1992): 155-163.

Greek Ministry of Transportation (www.yme.gov.gr).

Hensher D, and T. Raimond. "Estimation of Public Transport Fare Elasticities in the Sydney Region." Prepared by the Institute of Transportation Studies (ITS) for the Independent Pricing and Regulatory Tribunal of New South Wales, Research Paper No 7, 1996.

Johansen K.W. "Demand Elasticities for Local Public Transport in Norway." Norwegian Institute of Transport Economics, TOI-505/2001, 2001.

Karlaftis, M.G and I. Golias "Effect of Network Efficiency Parameters on Automobile Ownership." In Proceedings of the $7^{\text {th }}$ World Conference on Systemics, Cybernetics and Informatics, Orlando, FL, (2001): 409-413.

Karlaftis, M.G and I. Golias. "Automobile Ownership, Households Without Automobiles and Urban Traffic Parameters: Are They Related?" Journal of the Transportation Research Board: Transportation Research Record 1792, (2002): 29-35.

MAM. Urban Transport Development Study. Attiko Metro Planning Authority, Athens, Greece, 2000.

National Statistical Service of Greece (www.statistics.gr).

Nijkamp P. and G. Pepping. "Meta-Analysis for Explaining the Variance in Public Transport Demand Elasticities in Europe." Journal of Transportation and Statistics, (1998).

Oum T.H., W.G. Waters and J.S. Yong. "A Survey of Recent Estimates of Price Elasticities of Demand for Transport.” World Bank Working Paper WPS359, 1990.

Oum T.H., W.G. Waters and J.S. Yong. "Concepts of Price Elasticities of Transport Demand and Recent Empirical Estimates." Journal of Transport Economics and Policy 26 (2), (1992): 139-154. 
Rus de G "Public Transport Demand Elasticities in Spain." Journal of Transport Economics and Policy 24 (2), (1990): 189-201.

Washington, S. P., M.G. Karlaftis, and F.L. Mannering. Statistical and Econometric Methods for Transportation Data Analysis. Chapman \& Hall, New York, NY, 2003.

Konstantina Gkritza is a Ph.D. student in the Department of Transportation and Infrastructure Systems Engineering in the School of Civil Engineering at Purdue University, West Lafayette, Ind. She holds a degree in civil engineering (2001) from the National Technical University of Athens (NTUA), Greece, and an M.Sc. in transportation (2003) from Virginia Polytechnic Institute and State University, Virginia.

Ioannis Golias is professor in the Department of Transportation Planning and Engineering at the National Technical University of Athens (NTUA), Greece. He holds a degree in civil engineering (1977) from NTUA, Athens, Greece, a Diploma of Imperial College, an M.Sc. in Transportation and a Ph.D. in Transportation (1981) from Imperial College of Science and Technology, London, U.K. He has more than 25 years of experience in all aspects of planning and engineering, traffic engineering and safety. Dr. Golias is the author of a great number of published papers.

Matthew $\boldsymbol{G}$ Karlaftis is lecturer in the Department of Transportation Planning and Engineering at the National Technical University of Athens (NTUA), Greece. He holds civil engineering degrees from the University of Miami (B.Sc. 1993, M.Sc. 1994) and a Ph.D. (1996) in civil engineering (transportation) and applied mathematics from Purdue University, West Lafayette, Ind. 